\title{
Impact of Endoscopic Retrograde Cholangiopancreatography on Laparoscopic Cholecystectomy
}

\author{
Ramlah Ghazanfor ${ }^{1}$, Sara Malik ${ }^{2}$, Maham Tariq ${ }^{2}$, Mehwish Changeez ${ }^{2}$, Javaria Malik ${ }^{3}$, Khawaja Rafay \\ Ghazanfor ${ }^{4}$, Khadija Ghulam², Syed Waqas Hasan' ${ }^{2}$, Jahangir Sarwar Khan ${ }^{5}$ \\ ${ }^{1}$ Senior Registrar, Surgical Unit 1, Holy Family Hospital, Rawalpindi \\ ${ }^{2}$ Post Graduate Trainee, Surgical Unit 1, Holy Family Hospital, Rawalpindi \\ ${ }^{3}$ Senior Registrar, Medical Unit, DHQ Hospital, Rawalpindi \\ ${ }^{4}$ Medical Student, C.M.H Lahore \\ ${ }^{5}$ Professor and Head, Department of Surgery, Holy Family Hospital, Rawalpindi
}

\begin{abstract}
AB STRACT
Background: For Common Bile Duct (CBD) stones an Endoscopic Retrograde Cholangiopancreatography (ERCP) is done prior to cholecystectomy. However, the ideal timing of cholecystectomy following ERCP is still a matter of debate. The aim of the present study was to observe the possible impact of ERCP on subsequent laparoscopic cholecystectomy.

Material and Methods: This case control study was carried out in the Department of Surgery Unit 1, Holy Family hospital, Rawalpindi, from January 2018 to March 2019. A total number of 300 patients of symptomatic gallstones presenting to outpatient department were enrolled. Two groups, A (control group) and B (case group) were made on the basis of absence or presence of CBD stones, respectively. Group A underwent laparoscopic cholecystectomy within three working days of admission. In group B, ERCP was performed prior to cholecystectomy. Primary operating surgeon filled structured questionnaires for each patient immediately after surgery to compare operative differences between both groups. The baseline demographic details, clinical characteristics, laboratory investigations and perioperative findings of both groups were recorded. Means and percentages were calculated with $P$ value $<0.05$ regarded as statistically significant.

Results: Majority of patients in this study were females ( $81 \%)$ of middle age group $(42.5 \pm 15$ years). Biliary colic was most common presenting complaint in both groups (33\%). Dissection in triangle of Calot $(P=0.00)$ and removal of gallbladder from liver bed $(P=0.00)$ was significantly more difficult in group $B$ than $A$. Intra-abdominal lavage was also done more often in post ERCP group $(P=0.00)$. However procedural time did not vary between the two groups $(P=0.19)$.

Conclusion(s): Preoperative ERCP increases difficulty in laparoscopic cholecystectomy but does not prolong procedural time.
\end{abstract}

Key words: Choledocholithiasis, Endoscopic retrograde cholangiopancreatography, Laparoscopic cholecystectomy

Authors' Contribution:

1Conception; 2-3Literature research;

manuscript design and drafting; ${ }^{4}$ Critical Email:saramalik087@gmail.com

Article info:

Correspondence:

Received: July 18, 2019

analysis and manuscript review; Data

Accepted: March 18, 2020

analysis; 7,9Manuscript Editing.

Cite this article. Ghazanfor R, Malik S, Tariq M, Changeez M, Malik J, Ghazanfor KR, Ghulam

$K$, Hasan SW, Khan JS. Impact of Endoscopic Retrograde Cholangiopancreatography on

Laparoscopic Cholecystectomy. J Islamabad Med Dental Coll.2020; 9(1): 48-53.

\section{Introduction}

Gallbladder stones are one of the commonest ailment of our times with an almost 20 million affected annually in United States. ${ }^{1}$ Although initially asymptomatic, $1 \%$ of all these will become 
problematic, hence mandating cholecystectomy. ${ }^{2}$ Choledocholithiasis is one of the sequelae of gallstone disease with a prevalence of $15 \%$. This if left untreated might lead to pancreatitis, cholangitis or simple obstructive jaundice with its associated complications of hepatorenal shutdown or encephalopathy. ${ }^{3}$ Currently two step approach of ERCP (Endoscopic retrograde cholangiopancreatography) followed by laparoscopic cholecystectomy is considered gold standard treatment modality for Common Bile Duct (CBD) stones. ${ }^{4}$ Approximately 500,000 ERCPs are performed annually in the United States. ${ }^{5}$ Various techniques like sphincterotomy, needle knife sphincteroplasty, and balloon sweep and occlusion cholangiogram are performed as a part of this procedure. ${ }^{5}$ Although evading the hazards of open or laparoscopic CBD exploration, ERCP is still an invasive procedure. Post ERCP cholecystectomy is mandatory to avoid recurrence. ${ }^{6,7}$

The time interval between ERCP and laparoscopic cholecystectomy (LC) is a matter of debate. It can be performed during index admission or after interval of few weeks. Intervening early will be cost-effective for both the patient and hospital as it will reduce chances of recurrent stones. A directly applicable original health economic model analysis with minor limitations suggests that early laparoscopic cholecystectomy following ERCP for common bile duct stones is cost effective compared with delayed laparoscopic cholecystectomy. In fact, offering early cholecystectomy may reduce the number of readmissions, emergency operations, and length of stay. ${ }^{8}$

The other school of thought believes that ERCP being an invasive procedure causes inflammation in triangle of Calot. Thus, early laparoscopic cholecystectomy after ERCP can have higher chances of complications like uncontrolled hemorrhage and bile ducts or, duodenal injuries. It can also increase time of surgery and rates of conversion into open procedure. In this context, our study compared operative findings of laparoscopic cholecystectomy in patients who had or had not undergone ERCP prior to surgery.

\section{Material and Methods}

A total number of 300 patients presenting to the outpatient department of Surgical Unit 1, Holy Family hospital, Rawalpindi were prospectively enrolled in this study by simple consecutive sampling during January 2018 to March 2019. Patients were between 15-70 years of age and all had ultrasonic evidence of gallstones. They were divided into two groups. Group A ( $n=150)$ consisted of patients who had simple gallstone disease with no history of obstructive jaundice. Their liver functions tests and CBD diameters on ultrasound were normal. While Group B $(n=150)$ patients had choledocholithiasis established on either ultrasound or Magnetic resonance cholangiopancreatography (MRCP). LFT's were either normal or deranged in this group but did not affect diagnosis. All patients were admitted and allotted into respective groups by same team of qualified general surgeons. Anesthesia fitness and baseline investigations were done in all patients. Those falling outside the defined age group, with decapacitating comorbidities (active Myocardial Infarction, uncontrolled COPD, super-obese) and not undergoing laparoscopic cholecystectomy (perforated gall bladder, empyema, cholecystoduodenal fistula etc.) were excluded from the study.

After admission, group A underwent elective cholecystectomy within three working days. Group $B$ followed a two-step course. Initially ERCP was performed followed by laparoscopic cholecystectomy within next 48 hours. All ERCPs were performed by a single qualified gastroenterologist. Sphincterotomy and balloon sweep was done to clear CBD. Normal occlusion 
cholangiograms were confirmed at the end of all procedures. Those cases where ERCP failed to clear bile were treated by open CBD exploration and cholecystectomy. They were henceforth excluded from study. During surgery LC standard four port technique was used in all cases. All surgeries were performed by qualified laparoscopic surgeons of same seniority. Society of American Gastrointestinal Endoscopic Surgeons (SAGES) guidelines for laparoscopic cholecystectomy were followed for dissection of triangle of Calot and duplex view was achieved before ligating cystic duct and artery with titanium clips. Gall bladder fossa was dissected using monopolar electrocautery mounted on an $L$ hook. Post operatively, both groups received intravenous injections of ceftriaxone 1 gram (three doses) and injection ketorolac $10 \mathrm{mg}$ (two doses). All except those converted into open procedures got discharged early next morning after removal of drains. For data collection, structured questionnaires were filled for each patient immediately after surgery by primary operating surgeon. The baseline demographic details, clinical characteristics, laboratory investigations and perioperative findings of both groups were recorded. Means and percentages were calculated with $P$ value $<0.05$ regarded as statistically significant.

\section{Results}

Total number of 300 patients were included in our study. Majority of them were females and belonged to the middle age group (Table I). Most have been symptomatic for more than one year. All patients had various presenting complaints related to underlying gallstones summarized in Table II.

Preoperative laboratory investigations and ultrasound were performed in all patients as per hospital protocol. Serum amylase levels were checked to rule out active pancreatitis (Table II).

\begin{tabular}{|c|c|c|}
\hline Characteristics & Group A & Group B \\
\hline Mean Age (years) & $44+12.4$ & $41.32+17.77$ \\
\hline \multicolumn{3}{|l|}{ Gender $n(\%)$} \\
\hline Male & 20 (11.9) & $57(37.5)$ \\
\hline Female & $148(88.1)$ & $95(62.5)$ \\
\hline $\begin{array}{l}\text { Mean Duration of Gallstone } \\
\text { Disease (years) }\end{array}$ & $1.9 \pm 2.9$ & $1.8 \pm 2.33$ \\
\hline \multicolumn{3}{|l|}{ Chief Presenting Complaints (n) } \\
\hline Biliary colic & 55 & 45 \\
\hline Acute cholecystitis & 29 & 15 \\
\hline Previous history of pancreatitis & 19 & 21 \\
\hline Chronic cholecystitis & 45 & 35 \\
\hline History of jaundice & 2 & 34 \\
\hline
\end{tabular}

\begin{tabular}{|c|c|c|}
\hline & Group A & Group B \\
\hline \multicolumn{3}{|l|}{ Preoperative lab values } \\
\hline TLC & $8.9 \pm 2.81$ & $8.5 \pm 2.48$ \\
\hline STB & $1.02 \pm 0.5$ & $0.83 \pm 0.29$ \\
\hline ALT & $33.65 \pm 19.65$ & $33.65 \pm 19.65$ \\
\hline Alkaline phosphatase & $207.86 \pm 75.59$ & $207.86 \pm 75.59$ \\
\hline \multicolumn{3}{|l|}{ Comorbidities } \\
\hline Hypertension & $46(27.40 \%)$ & $39(25.7 \%)$ \\
\hline Diabetes Mellitus & $26(15.5 \%)$ & $9(5.9 \%)$ \\
\hline COPD & $6(3.6 \%)$ & $10(6.6 \%)$ \\
\hline \multicolumn{3}{|l|}{ BMI } \\
\hline Class 1 & $140(83.3 \%)$ & $124(81.6 \%)$ \\
\hline Class 2 & $24(14.3 \%)$ & $47(36.9 \%)$ \\
\hline Class 3 & $3(24 \%)$ & $19(12.5 \%)$ \\
\hline \multicolumn{3}{|l|}{ ASA LEVEL } \\
\hline Grade 1 & $88(52.4 \%)$ & $86(52.4 \%)$ \\
\hline Grade 2 & $56(33.3 \%)$ & $47(30.9 \%)$ \\
\hline Grade3 & $24(14.3 \%)$ & $19(12.5 \%)$ \\
\hline Cardiac Issues & 16 (9.5\%) & $10(6.6 \%)$ \\
\hline
\end{tabular}

TLC-Total leukocyte count; STB-Serum Total Bilirubin; ALTAlanine transaminase; $C O P D-C h r o n i c$ obstructive pulmonary disease; BMI-Body mass index; ASA-American Society of Anesthesiologists

Primary operating surgeon was required to answer several questions regarding difficulty in performing cholecystectomy and answers were recorded as "yes" or "no" (Table III). 


\begin{tabular}{|c|c|c|c|}
\hline & $\begin{array}{c}\text { Group A } \\
\text { n (\%) }\end{array}$ & $\begin{array}{c}\text { Group B } \\
\mathrm{n}(\%)\end{array}$ & $\begin{array}{c}P \\
\text { value* }\end{array}$ \\
\hline $\begin{array}{l}\text { Difficulty in } \\
\text { dissecting triangle } \\
\text { of Calot }\end{array}$ & $66(33.3)$ & $104(68.4)$ & 0.00 \\
\hline $\begin{array}{l}\text { Difficulty in } \\
\text { dissecting } \\
\text { gallbladder from } \\
\text { liver bed }\end{array}$ & $77(45.8)$ & $104(68.4)$ & 0.00 \\
\hline $\begin{array}{l}\text { Gall bladder fossa } \\
\text { bleeding after } \\
\text { cholecystectomy }\end{array}$ & 79 (59.5) & 95 (62.5) & 0.129 \\
\hline Need to wash & $55(32.7)$ & $104(68.4)$ & 0.00 \\
\hline $\begin{array}{l}\text { Conversion to open } \\
\text { procedure }\end{array}$ & $6(4.2)$ & 0 & 0.01 \\
\hline $\begin{array}{l}\text { Mean of total time } \\
\text { in minutes } \$\end{array}$ & $41.16 \pm 16.69$ & $43.65 \pm 17.35$ & 0.19 \\
\hline
\end{tabular}

*P value $<0.05$ was taken as statistically significant \$From insertion of umbilical port to retrieval of gallbladder from same site

\section{Discussion}

Laparoscopic cholecystectomy is the gold standard for treatment of symptomatic gallstones owing to lesser post-operative pain, earlier return to work and early mobility along with the additional benefits of better and magnified view. ${ }^{9}$ However, rate of operative complications if high will obviously nullify the benefits of minimally invasive technique. ${ }^{10}$

Currently SAGES is working on development of "Culture of safety in Cholecystectomy". Their goal is to develop laparoscopic cholecystectomy as a procedure in which neither the patient (iatrogenic injury) nor the doctor (litigation) suffers. ${ }^{10}$ Any ongoing inflammation in triangle of Calot can obviously increase the risk of procedural complications. ${ }^{11}$ This is especially relevant in cases where prior ERCP is performed for concomitant choledocholithiasis. Although minimally invasive, ERCP acts like a two- edged sword. Maneuvers like sphinteroplasty, CBD cannulation, balloon sweeps and Dormia basket retrieval can clear stones from $\mathrm{CBD}$, but induce surrounding inflammation, edema and adhesions formation. They can also trigger pancreatitis and peri-portal inflammation. ${ }^{7,8}$ Hence ERCP can potentially obscure normal anatomy. Several studies support that post-ERCP laparoscopic cholecystectomies are usually difficult because of the need for adhesiolysis and inflammation in Calot's triangle. ${ }^{6}$ According to multiple studies this can lead to longer operating time and higher risk of conversion to open surgery. ${ }^{9,10}$

A questionnaire was designed in this study to establish whether various steps were easy or difficult to perform during laparoscopy. It was answered by primary surgeon at end of every procedure. Researchers were well aware that perception of difficulty varies between different surgeons and those lacking necessary expertise will grade even a simple case as difficult one. To mitigate this bias, maximum surgeries were done by high volume laparoscopic surgeons (defined as $>$ 15 cases/year)..$^{12}$

In group $B$ (ERCP), significant difficulty was faced in dissecting triangle of Calot and in separating gallbladder from liver bed. Post cholecystectomy lavage was also performed more frequently in group $B$ than $A$.

Surprisingly, there was no significant difference in procedure time in both groups. Few international studies quote ERCP as one of the predisposing factors of conversion of laparoscopic to open procedure. ${ }^{13-15}$ In our study, conversion to an open procedure was done only in 3 cases with empye ma in one and perforated gall bladder in two cases. Some authors state that rate of conversion to open surgery wasn't affected by cholecystectomy following ERCP but by number of ERCPs a patient had undergone concluding that multiple ERCPs lead to higher chances of conversion to open procedure. ${ }^{11}$

Thus, the results of our study showed that prior ERCP can adversely influence dissection during LC. 
This is in contrast with few recent studies. In 2018, Fris et al published a meta-analysis in Scandinavian journal that recommended early surgery post ERCP declaring it safe. The systemic review of data pooled from 14 studies showed that postponing surgery up to 6 weeks post ERCP almost tripled the chances of conversion into open procedure. ${ }^{8}$ Similar conclusion was drawn by several other studies as well. ${ }^{16}$

In our study total hospital stay in both groups was between 4.5 to 7.4 days respectively. This was understandable as in addition to surgery, group $B$ patients had to wait for appointments with gastroenterology department as well, which in turn depended upon the availability of endoscope. Laparoscopic-endoscopic rendezvous can be one way to shorten the length of this stay. Although not available in our setup, this technique has been proved to be safe and effective world-wide. ${ }^{15-17}$ Another alternative is same-day two-stage approach where both ERCP and LC are performed within 24 hours of each other at the index admission. When done in suitable patients, this also improved patients' quality-of-life, prevented recurrence with a significant cost abatement. ${ }^{17}$

Thus in essence, those who endorse ERCP followed by laparoscopic cholecystectomy deem it safe and effective ${ }^{12}$ while the opponents claim that previous ERCP leads to a more complicated and lengthier cholecystectomy similar to the results of our study. ${ }^{13}$

\section{Conclusion}

Preoperative ERCP within 48 hours of laparoscopic cholecystectomy was associated with increased difficulty in dissecting triangle of Calot and liver bed but was not associated with longer procedural time or conversion to open surgery.

\section{References}

1. Zheng $Y, X u$ M, Heianza $Y$, Ma W5, Wang T3,4, Sun $D$, et al. Gallstone disease and increased risk of mortality: Two large prospective studies in US men and women. J Gastroenterol Hepatol. 2018, 33(11): 1925-31. Doi: 10.1111/jgh.14264

2. Zaliekas J, Munson JL. Complications of Gallstones: The Mirizzi Syndrome, Gallstone lleus, Gallstone Pancreatitis, Complications of "Lost" Gallstones. Surg Clin North Am. 2008, 88(6): 1345-68. Doi:10.1016/j.suc.2008.07.011

3. Portincasa P, Ciaula AD, Bari O, Garruti G, Palmieri VO, Wang DQ. Management of gallstones and its related complications. Expert Rev Gastroenterol Hepatol. 2016, 10(1): 93-112. Doi: 10.1586/17474124.2016.1109445

4. Wang CC, Tsai MC, Wang YT, Yang TW, Chen HY, Sung WW et al. Role of Cholecystectomy in Choledocholithiasis Patients Underwent Endoscopic Retrograde Cholangiopancreatography. Scientific reports. 2019 Feb 18;9(1):1-7. Doi: 10.1038/s41598 018-38428-z

5. Guda NM, Freeman ML. Overview of ERCP complications: prevention and management. InERCP and EUS. Springer, New York, NY. 2015: 37-56.

6. Boerma D, Rauws EA, Keulemans YC, Janssen IM, Bolwerk CJ, Timmer R et al.Wait-and-see policy or laparoscopic cholecystectomy after endoscopic sphincterotomy for bile-duct stones: a randomised trial. Lancet. 2002; 360(9335):761-5. Doi: 10.1016/S0140-6736(02)09896-3

7. Friis C, Rothman JP, Burcharth J, Rosenberg J. Optimal timing for laparoscopic cholecystectomy after endoscopic retrograde cholangiopancreatography: A Systematic Review. Scand J Surg. 2018, 107(2): 99-106. Doi: $10.1177 / 1457496917748224$

8. Ghadhban BR. Assessment of the difficulties in laparoscopic cholecystectomy among patients at Baghdad province. Ann Med Surg. 2019, 41: 16-9. Doi: 10.1016/j.amsu.2019.03.008

9. Gupta V, Jain G. Safe laparoscopic cholecystectomy: Adoption of universal culture of safety in cholecystectomy. World J Gastrointest Surg. 2019, 11(2): 62-84. Doi: 10.4240/wjgs.v11.i2.62

10. Kama NA, Doganay $M$, Dolapci $M$, Reis $E$, Atli $M$, Kologlu M. Risk factors resulting in conversion of laparoscopic cholecystectomy to open surgery. Surg Endosc. 2001; 15: 965-68. Doi: 10.1007/s00464-0010008-4

11. Csikesz NG, Singla A, Murphy MM, Tseng JF, Shah SA. Surgeon volume metrics in laparoscopic 
cholecystectomy. Dig Dis Sci. 2010; 55(8): 2398-405. Doi: 10.1007/s10620-009-1035-6

12. Chauhan S, Masood S, Pandy A. Preoperative predictors of conversion in elective laparoscopic cholecystectomy. Saudi surg J. 2019; 7(1): 14-19. Doi: 10.4103/ssj.ssj_37_18

13. Ercan M, Bostanci EB, Teke Z, Karaman K, Dalgic T, Ulas $M$, et al. Predictive factors for conversion to open surgery in patients undergoing elective laparoscopic cholecystectomy. J Laparoendosc Adv Surg Tech. 2010; 20(5): 427-34. Doi:10.1089/lap.2009.0457

14. Loor MM, Morancy JD, Glover JK, Beilman GJ, Statz CL. Single-setting endoscopic retrograde cholangiopancreatography (ERCP) and cholecystectomy improve the rate of surgical site infection. Surg Endosc. 2017; 31(12):5135-42. Doi:10.1007/s00464017-5579-9
15. Rosen M, Brody F, Ponsky J: Predictive factors for conversion of laparoscopic cholecystectomy. Am J Surg. 2002; 184(3):254-8. Doi: 10.1016/s00029610(02)00934-0

16. Vettoretto N, Arezzo A, Famiglietti F, Cirocchi R, Moja L, Morino M. Laparoscopic-endoscopic rendezvous versus preoperative endoscopic sphincterotomy in people undergoing laparoscopic cholecystectomy for stones in the gallbladder and bile duct. Cochrane Database Syst Rev. 2018; 4: CD010507. Doi: 10.1002/14651858.CD010507

17. Borreca D, Bona A, Bellomo MP, Borasi A, De Paolis P. "Ultra-rapid" sequential treatment in cholecystocholedocholithiasis: alternative same-day approach to laparoendoscopic rendezvous. Updat Surg. 2015; 67(4):449-54. Doi: 10.1007/s13304-0150339-7 